\title{
EL 2018 EN MYANMAR
}

Luisa Alejandra González Barajas

El Colegio de México

La República de la Unión de Myanmar, también conocida como Birmania, se ubica en la parte continental del sureste asiático. Comparte frontera con India y Bangladesh al oeste, con China al norte y noreste, con Tailandia y Laos al oeste, y al sur limita con la bahía de Bengala y el mar de Andamán. Según estimaciones de la CIA (2018), Myanmar cuenta con una población de más de 55 millones de habitantes, distribuidos en alrededor de 676500 kilómetros cuadrados.

Si bien el gobierno reconoce 135 grupos étnicos, el grueso de la población presenta las siguientes características: bamar $68 \%$, shan $9 \%$, karen $7 \%$, rakhine $4 \%$, chinos 3\%, indios $2 \%$, mon $2 \%$, otros $5 \%$. Territorialmente, y atendiendo a los grupos étnicos dominantes que ahí habitan, Myanmar se divide en siete estados o pyi (Rakhine, Chin, Kachin, Shan, Kayah, Kayin y Mon) y siete divisiones o taing (Sagaing, Tanintharyi, Ayeyarwady, Yangon, Bago, Magway y Mandalay). 
MAPA 1. Estados y divisiones en Myanmar

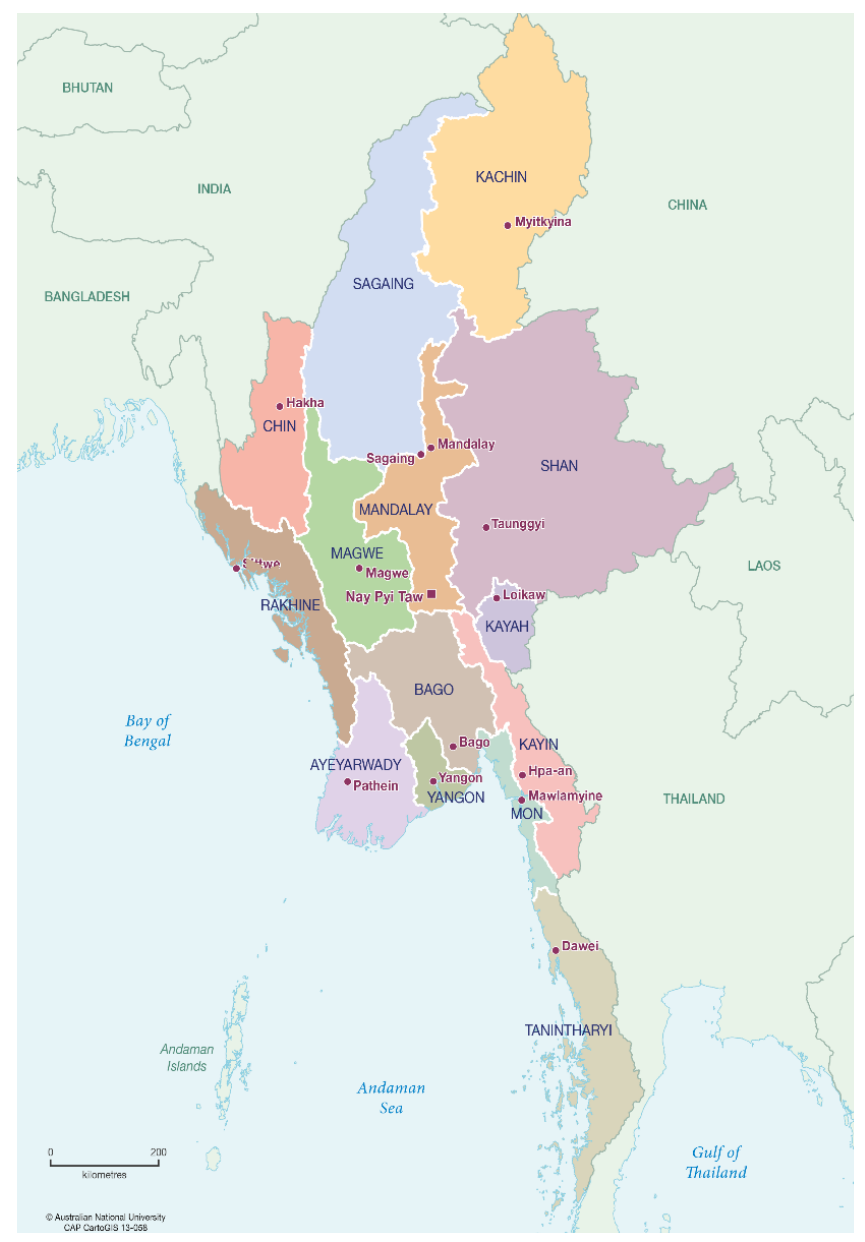

FUENTE: (ANU), Australian National University, 28 de septiembre de 2018. Obtenido de Maps Online, ANU College of Asia and the Pacific:

http://asiapacific.anu.edu.au/mapsonline/base-maps/myanmar-statesregions

Respecto a la religión, el último censo, realizado en 2014, indicó las siguientes tendencias: $87.9 \%$ budista, $6.2 \%$ cristiano, $4.3 \%$ musulmán, $0.8 \%$ animista, $0.5 \%$ hindú, $0.2 \%$ otro, $0.1 \%$ ninguno. 
GRÁFICA 1. Afiliación religiosa en Myanmar

Religious affiliation (2014)

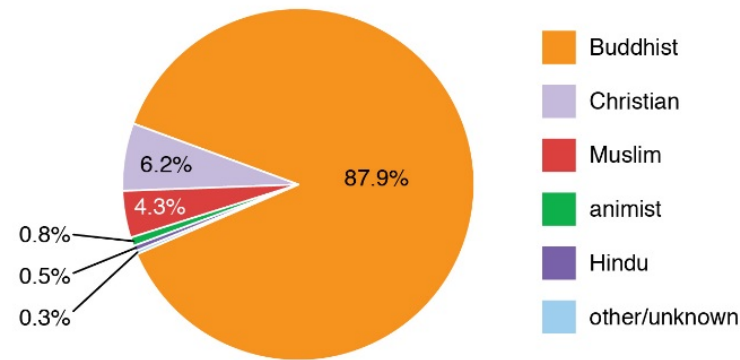

๑ Encyclopædia Britannica, Inc

FUENTE: Encyclopædia Britannica (5 de octubre de 2018), Myanmar: Religious affiliation. Disponible en:

https:/www.britannica.com/place/Myanmar/Languages/media/400119/224192

Myanmar obtuvo su independencia del Reino Unido en 1948, luego de más de seis décadas de dominación. El gobierno democrático de la nación independiente sobrevivió por un breve periodo, luego de que un golpe de Estado llevara a los militares al poder en 1962. Después de casi cinco décadas de gobierno militar autocrático, Myanmar inició una lenta transformación hacia una democracia representativa en 2011, y más aceleradamente a partir de 2016. No obstante, algunas tensiones nacionales amenazan la débil transición y la estabilidad del país. Su composición étnica y religiosa, así como su historia política, son variables fundamentales que dan cuenta de las problemáticas a las que se enfrenta el país en la actualidad.

El recuento de 2018 en Myanmar que aquí nos ocupa se centrará en cinco temas principales: la figura de Aung San Suu Kyi, la elección del nuevo presidente de la Unión, los rohingya, los kachin, y el caso de los reporteros de Reuters. Se espera con ello que el lector o la lectora comprenda en términos generales qué está sucediendo en Myanmar.

En la primera sección se exponen los retos a los que se ha enfrentado una figura emblemática de la lucha democrática en Myanmar: Aung San Suu Kyi, la consejera de estado que en un intento por mantener la estabilidad interna en un gobierno civil de poder 
compartido con los militares ha sido duramente criticada por su pasividad ante los abusos a las minorías rohingya y rakhine, así como por su apoyo a la sentencia de dos periodistas de Reuters. La segunda sección hará un breve recuento sobre la elección del nuevo presidente, Win Myint, sus antecedentes y sus vínculos con la élite gobernante que apoyó su candidatura. $\mathrm{Su}$ elección y la transferencia pacífica del poder sientan un importante precedente democrático, pero la duda permanece sobre su capacidad de acción, especialmente si consideramos que se encuentra a la sombra de Aung San Suu Kyi.

Las secciones restantes pueden entenderse como los temas principales que ocuparon gran parte de la atención en 2018. El caso de los rohingya en el estado Rakhine es, en definitiva, el más destacado por su magnitud, apoyo internacional, justificación y omisión. El tema de los kachin, aunque no es reciente, ha sido opacado y al mismo tiempo visibilizado por la crisis en Rakhine, y aunque son problemáticas en naturaleza distintas — en tanto los kachin son un grupo étnico reconocido por el gobierno y son desplazados internos ${ }^{1}$ y no refugiados-, se han visto de cierta manera interconectadas. Finalmente, el asunto de la libertad de prensa y la censura periodística no ha hecho mas que endurecer las críticas hacia el gobierno birmano en general y hacia Aung San Suu Kyi en particular.

Dentro del panorama que aquí se presenta debe leerse entre líneas y considerar en todo momento la influencia que aún tienen los militares, especialmente en un momento en que se presentan como protectores y estabilizadores ante la amenaza y la desobediencia civil, con lo que renuevan su imagen y se benefician en todo momento del status quo de poder compartido.

\section{El Gobierno DE Aung SAn SuU KyI}

Aung San Suu Kyi, quien permaneció quince años en arresto domiciliario durante el gobierno militar, salió del aislamiento como una heroína. La también Premio Nobel de la Paz cofundó en 1988 la Liga Nacional para la Democracia (LND), partido que arrasó en las elecciones de 2015, logró la mayoría en el parlamento y pudo imponer a su candidato en el ejecutivo. Ante el impedimento constitucional para tomar la presidencia (estuvo casada con un extranjero y

${ }^{1}$ De acuerdo con la Agencia de las Naciones Unidas para los Refugiados (ACNUR), las personas desplazadas internamente (PDI), a diferencia de los refugiados, no han cruzado una frontera para encontrar seguridad, sino que permanecen dentro de su propio país bajo la protección de su gobierno, incluso si ese gobierno es la razón de su desplazamiento (UNHCR, 2018). 
tiene dos hijos de nacionalidad británica), Aung San Suu Kyi creó el puesto de consejera de Estado. Muchos guardaban esperanzados su llegada al poder en 2016.

Sin embargo la tan aclamada "diosa de la democracia" enfrenta hoy a una comunidad internacional decepcionada y aterrorizada ante las atrocidades cometidas por su gobierno, de la mano de los militares, en contra de las minorías étnicas — en especial los musulmanes rohingya y los cristianos kachin - y la censura periodística que por varios años ha sido constante en Myanmar, pero que hoy se visibiliza y se condena ante las absurdas justificaciones. Si bien Aung San Suu Kyi ha declarado en más de una ocasión que está en desacuerdo con que la consideren como un "ícono de la democracia", y que prefiere que la vean como una política birmana, lo cierto es que ha utilizado esta imagen de manera eficaz en distintos escenarios. Steinberg sugiere que es ambas cosas, aunque "su papel político interno y frágil ha arruinado su legado internacional" (Steinberg, 2018).

El margen de maniobra política del gobierno civil se ha constreñido en gran medida por el poder de las fuerzas armadas (tatmadaw) que controlan los ministerios de defensa, asuntos internos y asuntos fronterizos. A ello se suma la Constitución de 2008, que les asegura un cuarto de los escaños parlamentarios, suficiente para bloquear cualquier tipo de reforma que atente contra sus intereses. A pesar del control de facto que tiene el tatmadaw, el gobierno civil tiene aún la capacidad de promulgar, reformar o abrogar leyes que se encuentran fuera de su jurisdicción, en especial aquéllas remanentes de la dictadura militar y del gobierno colonial.

De acuerdo con Thet Swe Win, integrante de la nueva generación de activistas en Myanmar, "el gobierno tiene la responsabilidad de guiar al pueblo a una democracia real. Pero parecen no querer hacerlo" (Kuhn, 2018). Para Maung Saungkha, defensor de la libertad de expresión y preso político durante el gobierno anterior, "si el gobierno continúa de esta manera, nunca lograremos la democracia y volveremos a ser una dictadura". Hay quienes afirman incluso que "reprimir las críticas se ha convertido en el sello del liderazgo" de Aung San Suu Kyi (Paddock, 2018).

Bill Richardson —excongresista, gobernador de Nuevo México, secretario de energía, embajador de Estados Unidos ante la ONU y miembro del Comité para la Implementación de las Recomendaciones en el estado Rakhine- escribió en la revista Time, a principios de año, que Aung San Suu Kyi "no ha comprendido la seriedad de los desafíos que enfrenta su país, 
ni la voluntad política para tratar de resolver la crisis en el estado Rakhine". Destacó que la líder "no ha mostrado un liderazgo moral y parece no estar dispuesta a escuchar ningún consejo" (Richardson, B., 2018). ${ }^{2}$

En entrevista con Mishal Husain, de la BBC, Aung San Suu Kyi justificó la violencia que sufre su país como consecuencia del "ambiente de miedo", y negó que los musulmanes fueran objeto de limpieza étnica: "Los musulmanes han sido atacados, pero los budistas también. Es este miedo lo que genera problemas, resultado de nuestros sufrimientos bajo un régimen dictatorial que forjó desconfianza". Además, en repetidas ocasiones ha apuntado a una "falta de comprensión" sobre las complejidades alrededor de la situación de los musulmanes rohingya, y ha citado la ausencia del "estado de derecho" como la raíz de muchos de los problemas en el país (BBC, 2018).

Por ahora, parece que Aung San Suu Kyi se ha enfocado en lograr que los militares cooperen con el gobierno civil para alcanzar su meta de reforma constitucional e instituir un sistema federal (Kuhn, 2018). En un intento por disipar los rumores de que las relaciones entre el gobierno civil y los militares se habían deteriorado lo suficiente como para existiera el temor de un golpe de estado, Aung San Suu Kyi dijo que sus relaciones con los militares no eran malas, y que los tres generales en el gabinete eran "bastante dulces" (John y Ungku, 2018) (BBC, 2018). Su postura conciliatoria, y en ocasiones cómplice, hacia los militares, ha encendido las alertas en algunos analistas que afirman que la transición democrática en Myanmar parece haberse estancado.

Durante el Foro Económico Mundial sobre la ANSEA (Asociación de Naciones del Sureste Asiático) en Hanói, el exministro de Relaciones Exteriores de Noruega y presidente del FEM, Borge Brende, preguntó a Aung San Suu Kyi si las circunstancias actuales eran muy diferentes a aquello que había anticipado, a lo que la consejera respondió que "la política es la política", y aunque "la gente suele pensar que la política de la oposición es diferente de la política en el cargo, la realidad es que no". Aseguró además que la "gente tiene mayor

2 El Comité para la Implementación de las Recomendaciones en el estado Rakhine sufrió un revés cuando Bill Richardson, uno de los cinco miembros internacionales originales, abandonó su primera ronda de reuniones en enero, luego de calificarlas de "operación de porrista" y de "encubrimiento" para Aung San Suu Kyi. Después de su renunciar, Richardson acusó a Aung San Suu Kyi de carecer de "liderazgo moral”. La oficina de la consejera de Estado expresó que Richardson estaba "siguiendo su propia agenda", y que se le pidió que abandonara el panel (McPherson y Naing, 2018). 
confianza en sí misma, mientras que los funcionarios públicos sienten que pueden tomar más la iniciativa y que serán escuchados” (Tan Hui Yee, 2018).

En 2018, a Aung San Suu Kyi le revocaron numerosos premios y honores internacionales debido a las actitudes de su gobierno. Entre los más destacado se encuentran el premio de derechos humanos otorgado por el Museo del Holocausto de los Estados Unidos; el premio a la libertad de Edimburgo; los premios de algunas ciudades de Reino Unido como Oxford, Glasgow y Newcastle, y una placa en Aberdeen, en el parque de Hazlehead Park (BBC, 2018) (Dangerfield, 2018). Por su parte, el parlamento canadiense votó de manera unánime para revocar la ciudadanía honorífica de Aung San Suu Kyi en respuesta a su incapacidad para detener la persecución de la minoría rohingya en su país. Los legisladores canadienses dijeron "reconocer que estos crímenes constituyen un genocidio", e instaron al consejo de seguridad de la ONU a remitir el caso a la Corte Penal Internacional (CPI), al tiempo que exigieron la investigación y el procesamiento de los involucrados "por el crimen de genocidio" (AFP, 2018). Respecto al Premio Nobel de la Paz, el jefe de la Fundación, Lars Heikensten, expresó que "no tenía sentido retirar premios en respuesta a las acciones posteriores a la entrega de éstos, pues los jueces tendrían que discutir constantemente los méritos de los galardonados". El Comité Noruego del Nobel que otorga el Premio de la Paz dijo en agosto que sus reglas no permitían que se retiraran los premios otorgados (Reuters, 2018).

Los críticos del gobierno civil en general, y de Aung San Suu Kyi en particular, enfatizan que hay mucho más que podrían hacer para promover la democracia y proteger los derechos humanos y la libertad de expresión, incluso con poderes limitados. Mientras que la comunidad internacional ha condenado la falta de voluntad de Aung San Suu Kyi para solucionar los problemas que aquejan a su país, el tatmadaw ha cosechado en silencio todos los beneficios de la inestabilidad con el apoyo mayoritario de la población budista.

\section{NUEVO PRESIDENTE DE LA UNIÓN}

El presidente de la República de la Unión de Myanmar, Htin Kyaw, dejó su cargo con efecto inmediato el 21 de marzo, "para descansar de los deberes y responsabilidades actuales" luego de presentar problemas de salud. La oficina del ahora expresidente anunció la renuncia en un comunicado que fue publicado en Facebook. En concordancia con la Constitución, el 
vicepresidente con más experiencia, Myint Swe, tomó el puesto como presidente interino hasta que el parlamento eligió al nuevo líder (Richards, 2018) (Slodkowski y Thu Thu Aung, 2018).

En las elecciones parlamentarias del 28 de marzo, Win Myint, el vicepresidente seleccionado como candidato presidencial por la cámara baja, respaldado por la LND, recibió 403 de 636 votos; Myint Swe, el vicepresidente apoyado por los militares, obtuvo 211 votos, mientras que Henry Van Tio, el vicepresidente seleccionado por la cámara alta, logró 18 votos. Al igual que su predecesor, Win Myint es miembro de la LND y aliado de Aung San Suu Kyi desde hace ya algunos años (Agerholm, 2018; Channel News Asia, 2018).

El parlamento eligió a Win Myint luego de una sesión de dos horas en la que no se mencionaron ni su carácter ni sus habilidades para el puesto. Tampoco se discutió su postura sobre temas apremiantes, como la situación de los rohingya, los problemas en el ámbito de la libertad periodística y de expresión, las dificultades económicas y la lucha continua entre militares y diversos grupos étnicos (Paddock y Nang, 2018). ${ }^{3}$

Win Myint juró como el décimo presidente el 30 de marzo. En su primer discurso ante el parlamento dijo que su administración estaría acorde con el imperio de la ley, y que buscaría lograr la reconciliación nacional y "enmendar la constitución para alcanzar una unión federal democrática". Además, afirmó que trabajaría para proteger los derechos humanos (AFP, 2018).

A pesar de las expectativas que algunos tenían en el nuevo presidente, sus primeros meses de gobierno no han demostrado todo aquello de lo que se dijo capaz, ni se han vislumbrado indicios de que pudiera ocurrir algún cambio efectivo, especialmente porque permanece a la sombra de los militares y porque el papel de presidente ha sido en gran parte ceremonial desde 2016, con Aung San Suu Kyi como la líder de facto en la administración civil.

${ }^{3}$ Después de una trayectoria de 30 años que lo ha llevado de la abogacía al activismo apolítico, para posteriormente convertirse en legislador y más recientemente en vocero de la Cámara Baja, Win Myint tomó posesión como el nuevo presidente de Myanmar. Como muchos otros activistas y políticos, Win Myint fue arrestado varias veces durante el régimen militar (San Yamin Aung, 2018). 


\section{LOS MUSULMANES ROHINGYA EN RAKHINE}

Los rohingya son un grupo étnico musulmán que habita originalmente en el estado birmano occidental de Rakhine, particularmente en los municipios de Maungdaw y Buthidaung. Tienen su propio idioma y cultura y afirman ser descendientes de comerciantes árabes y otros grupos asentados en la región desde hace ya varias generaciones. Sin embargo, el gobierno los considera migrantes bengalíes y la población budista apoya en su mayoría dicha postura. ${ }^{4}$

Un factor importante que contribuyó a la crisis actual en Rakhine se remonta a la Segunda Guerra Mundial. Durante la ocupación japonesa, los budistas en Arakan (hoy Rakhine) fueron reclutados para luchar a favor de los japoneses. Los musulmanes, por su parte, lucharon del lado de los británicos; este antecedente marcaría su futuro como musulmanes rohingya, pues con el fin de la guerra, y alcanzada la independencia, los rohingya se enfrentaron a oleadas de violencia gubernamental y a la expulsión territorial, especialmente a partir de 1962, cuando los militares tomaron el poder.

Pero el momento crucial llegó en 1982 con la declaración de la "ley de ciudadanía", que reconoció oficialmente a 135 grupos étnicos o razas nacionales, pero los rohingya no se incluyeron en la lista. Con esta ley, en vigor a partir de 1987, el gobierno los consideró "migrantes económicos" que se habían asentado en Rakhine durante el periodo colonial, además de que los convirtió en apátridas y les negó cualquier derecho de ciudadanía, como estudiar, trabajar, viajar, casarse, practicar su religión o tener acceso a servicios de salud (Kipgen, 2013).

${ }^{4}$ El budismo se utilizó para consolidar la identidad nacional durante varios siglos. Desde su fundación, Myanmar fue en su mayoría budista y étnico-bamar: los reyes apoyaban el monacato (sangha) a cambio de conceder legitimidad a la monarquía. Los monjes fomentaron la lealtad hacia el gobierno, pero también sirvieron como su conciencia, asegurándose de que se siguieran los principios éticos budistas. Cuando no fue así, éstos se rebelaron — como sucedió durante la revolución del azafrán de septiembre de 2007.

${ }^{5}$ Esta ley creó tres categorías de ciudadanía: ciudadanía, ciudadanía asociada y ciudadanía naturalizada. La ciudadanía se otorga a aquéllos que pertenecen a una de las razas nacionales como Kachin, Kayah (Karenni), Karen, Chin, Burman, Mon, Rakhine, Shan, Kaman o Zerbadee. La ciudadanía asociada se otorga a los que no pueden demostrar que sus antepasados se asentaron en Myanmar antes de 1823, pero pueden demostrar que tienen un abuelo o ancestro anterior a 1823, que era ciudadano de otro país, así como personas que solicitaron la ciudadanía en 1948 y calificado entonces por esas leyes. La ciudadanía naturalizada sólo se otorga a quienes tienen al menos un padre con uno de estos tipos de ciudadanía birmana o puede proporcionar "evidencia concluyente" de que sus padres ingresaron y residieron en Birmania antes de la independencia en 1948. 
MAPA 2. Población rohingya en el mundo

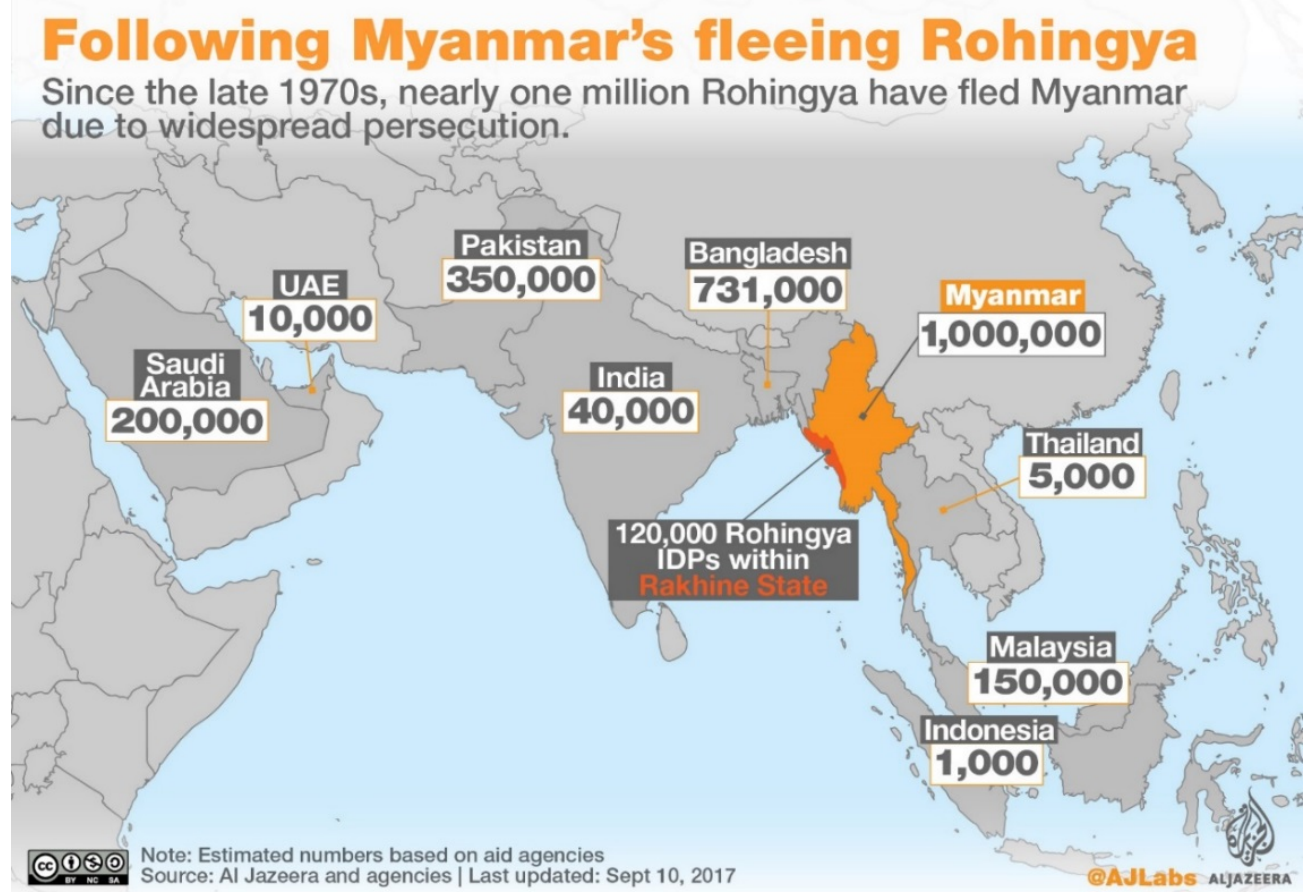

FUENTE: Al Jazeera (2017), UN rights chief denounces Myanmar's ethnic cleansing, Al Jazeera, 12 de septiembre. Obtenido de: https://www.aljazeera.com/news/2017/09/myanmar-crisis-textbook-ethnic-cleansing170911081528888.html

Por décadas el gobierno militar manipuló el temor por una supuesta "desaparición del budismo" y la "ruptura de la nación", para asegurar la lealtad de una población resentida, y al mismo tiempo, mantuvo el monopolio de la violencia e imposibilitó a los ciudadanos al desestabilizar al gobierno con disturbios sociales. Irónicamente, fue con el proceso de transición democrática, en 2011, cuando la tensión entre budistas y musulmanes resurgió, ahora con el apoyo de monjes extremistas. ${ }^{6}$ El censo Población y Vivienda 2014, que excluyó a las minorías extranjeras de las votaciones de 2015, marginó políticamente a los rohingya y

${ }^{6}$ El nacionalismo budista y la islamofobia cobraron fuerza con apoyo de algunos monjes budistas; el más conocido de éstos es Ashin Wirathu, líder de la Organización para la Protección de la Raza y la Religión, o Ma Ba Tha, por sus siglas en birmano, asociación fundada en junio de 2013 que encontró rápidamente el apoyo de millones de budista birmanos. El nombre de la organización $M a B a$ Tha deriva del grito popular de lucha anticolonial Amyo, Batha, Thathana (raza, idioma y religión). Aunque el budismo no es una raza, $M a B a$ Tha a menudo combina raza y religión, lo que demuestra que la preocupación más profunda del grupo es la etnia. 
al resto de los musulmanes, pues por primera vez desde la independencia no lograron ninguna representación en el parlamento.

El ataque del grupo armado rohingya a un puesto policial cerca de Maungdaw, en octubre de 2016, seguido de un llamado a la jihad, avivó el temor y legitimó las represalias del tatmadaw mediante una campaña de contrainsurgencia. La situación en el estado Rakhine se deterioró notablemente a partir del 25 de agosto de 2017, cuando un comando del Ejército de Salvación Arakan Rohingya (ARSA, por sus siglas en inglés) lanzó un ataque coordinado contra treinta puestos de la policía fronteriza, en el que murió una docena de fuerzas de seguridad, lo que desencadenó otra ola de violencia coordinada por el tatmadaw en todo el estado Rakhine. La "campaña de tierra arrasada" ha exterminado al menos cincuenta y cinco aldeas - y eliminado rastros de edificios, pozos e incluso vegetación —, asesinado a miles de rohingya y llevado a cientos de miles de pobladores a exiliarse en Bangladesh (Al Jazeera, 2018; AP, 2018; Wa Lone y Shoon Naing, 2017). 
MAPA 3. Villas destrozadas en los asentamientos de Maungdaw,

Buthidaung y Rathedaung

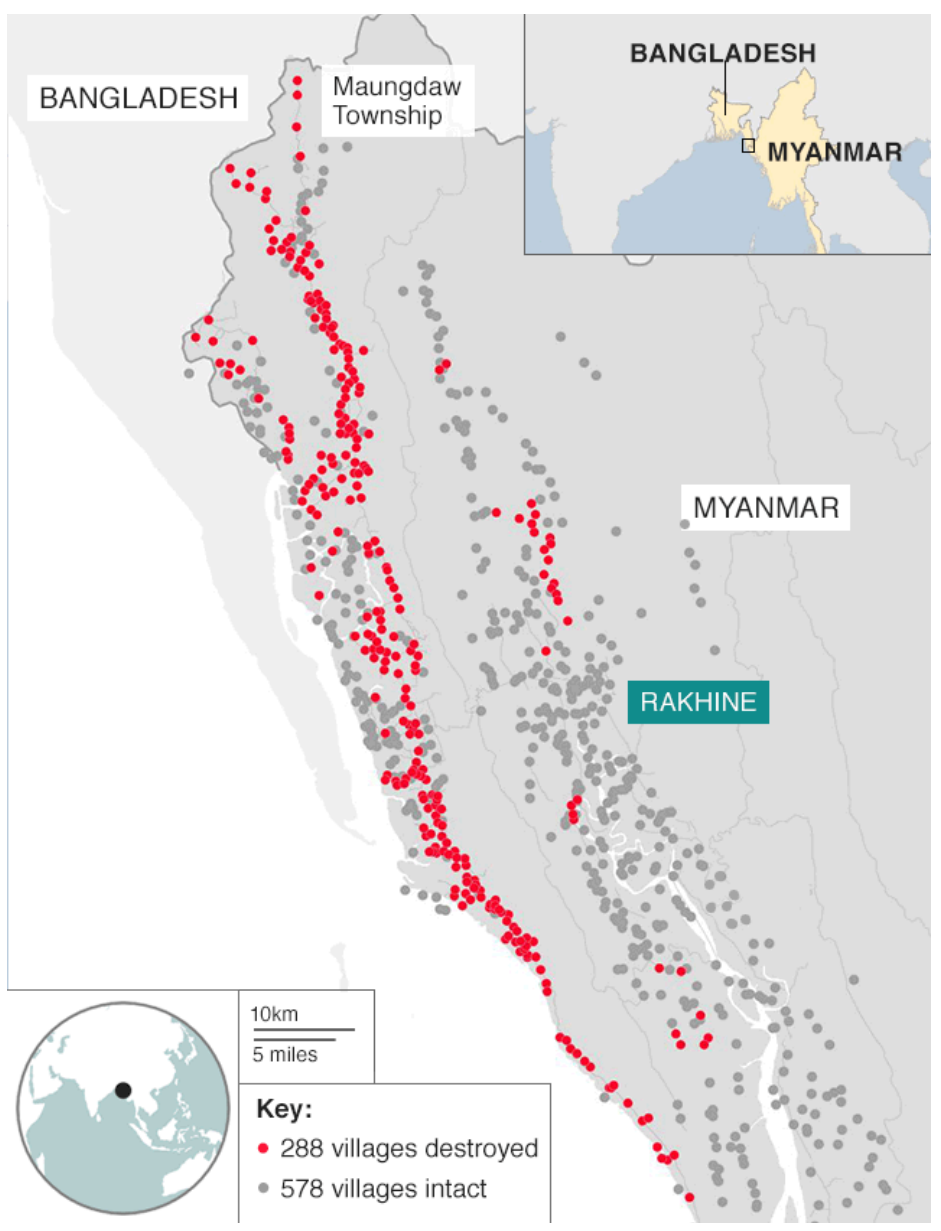

FuENTE: Human Rights Watch (2017), Burma; New Satellite Images Confirm Mass Destruction, Human Rights Watch, 17 de octubre. Obtenido de: https:/www.hrw.org/news/2017/10/17/burma-new-satellite-images-confirm-massdestruction

Human Rights Watch afirma que la mayoría de los daños ocurrieron en el municipio de Maungdaw entre el 25 de agosto y el 25 de septiembre de 2017, con muchas aldeas destruidas después del 5 de septiembre, luego de que el gobierno informara que las operaciones del tatmadaw habían terminado (Human Rights Watch, 2017). Según cálculos de The Irrawaddy, alrededor de 90\% de la población rohingya ha huido a Bangladesh desde el año pasado (Moe Myint, 2018). 
La agencia de ayuda Médecins Sans Frontières, que trabaja en lo que hoy es el campamento de refugiados más grande del mundo, en el extremo sur de Bangladesh, Cox's Bazar, estima que alrededor de 6700 rohingya fueron asesinados durante el primer mes de violencia. La Organización Internacional para las Migraciones advirtió que al menos 688000 personas han huido hacia Cox's Bazar desde agosto de 2017 (Baldwin, 2018), aunque algunos mencionan que son más de 730000 los refugiados.

De acuerdo con el Alto Comisionado de las Naciones Unidas para los Derechos Humanos (ACNUDH), Zeid Ra'ad al-Hussein, las cosas han empeorado de manera exponencial en Rakhine desde 2017, lo que ha causado "un ejemplo clásico de limpieza étnica" (UN News, 2017) que apunta hacia aparentes "actos de genocidio" en contra los rohingya (Tun Khin, 2018). En su discurso ante la ONU en septiembre de 2017, Zeid Ra'ad al-Hussein pidió al gobierno de Myanmar poner fin a la "operación de seguridad brutal" en contra rohingya y "revertir el patrón de discriminación severa y generalizada contra la población" (Al Jazeera, 2017).

El 16 de enero, Myanmar y Bangladesh firmaron un acuerdo en el que se comprometieron a completar la repatriación voluntaria de los refugiados en un plazo de dos años; sin embargo, el proceso se ha retrasado repetidamente, pues ambas partes se culpan de "falta de preparación". En abril una familia de refugiados se convirtió en la primera en ser repatriada; la acción se produjo a pesar de las advertencias de la ONU y de otros grupos de derechos humanos, de que "una repatriación masiva, antes de solucionar los problemas de discriminación y persecución que los rohingya han enfrentado durante décadas, es prematura" (Safi, 2018). Tan sólo un mes antes de la primera repatriación, en un discurso ante el personal militar y sus familias en el estado Kachin, el comandante en jefe de las fuerzas armadas birmanas, general Min Aung Hlaing, expresó que los rohingya "no tienen ninguna característica o cultura en común con las etnias de Myanmar" y que las tensiones en Rakhine fueron provocadas, "porque los bengalís exigen la ciudadanía". El secretario general de la ONU, António Guterres, expresó su preocupación ante los comentarios de Min Aung Hlaing e instó a todos los líderes en Myanmar "a tomar una postura unificada contra la incitación al odio y a promover la armonía comunitaria” (Lee, Aye Win Myint y Shoon Naing, 2018.

La Comisión de Derechos Humanos de la ONU estableció en marzo una misión internacional para que investigara las denuncias de abusos cometidos por los militares y los 
cuerpos de seguridad birmanos. Además, las agencias de la ONU y sus ONG asociadas emitieron un plan de respuesta conjunta para atender "la crisis de refugiados con mayor crecimiento en el mundo" (Wai Mar Tun, 2018).

"Por lo que he visto y escuchado de la gente, las condiciones no son propicias para el retorno", dijo Ursula Mueller, secretaria general adjunta de asuntos humanitarios de la ONU después de una visita de seis días a Myanmar a principios de abril (Reuters, 2018). Sin embargo, Aung San Suu Kyi afirmó poco después que Myanmar estaba listo para recibir a los refugiados rohingya, “debidamente verificados" (South China Morning Post, 2018). Ante las continuas negaciones de irregularidades por parte de las autoridades birmanas, no sorprende que muchos de los refugiados tengan pocos deseos de regresar. Una encuesta publicada en mayo por la Xchange Foundation, encargada de investigar y documentar la migración humana, encontró que de los más de 1700 rohingya entrevistados, el 97.5\% regresaría a Myanmar sólo si se les otorga la ciudadanía, libertad de movimiento y de religión. Sin embargo el gobierno ha dado pocos indicios de estar dispuesto a acceder a esas demandas (Beech H., Myanmar and U.N. Agree to Aim forRepatriation of Rohingya, 2018).

En mayo, la relatora especial sobre la situación de los derechos humanos en Myanmar, Yanghee Lee, insistió en una declaración de prensa que todas las partes en el conflicto deberían respetar el derecho internacional humanitario y tomar precauciones para no dañar a los civiles (UN News, 2018). Por su parte, Phil Robertson, director adjunto para Asia de Human Rights Watch, afirmó que el país "tiene un largo camino por recorrer antes de poder demostrar que las reformas necesarias para la repatriación son un hecho" (Human Rights Watch, 2018).

La agencia de las Naciones Unidas para los refugiados (Alto Comisionado de las Naciones Unidas para los Refugiados, ACNUR) y el Programa de las Naciones Unidas para el Desarrollo (PNUD) acordaron, el 31 de mayo, en colaboración con el gobierno de Myanmar, el texto del memorando de entendimiento tripartito, un marco de cooperación destinado a crear las condiciones propicias para la repatriación voluntaria, segura, digna y sostenible de los refugiados rohingya a sus lugares de origen o a donde ellos elijan. ${ }^{7}$ Después de que se

${ }^{7}$ Se considera un progreso sustancial en tres áreas clave: acceso al estado Rakhine, libertad de movimiento para todas las comunidades, y tratar las causas fundamentales de la crisis (UNHCR, 2018). El 13 de abril, el gobierno de Bangladesh y la ACNUR habrían firmado también un memorándum relacionado con el retorno voluntario de los refugiados rohingya luego de que las condiciones en Myanmar les fueran propicias (ACNUR, 2018). 
filtrara el texto del memorándum, líderes y activistas rohingya exclamaron que "no reflejaba un compromiso del gobierno birmano para cumplir con demandas clave como condición previa para el regreso seguro", por lo que estaba "en contra del interés de los rohingya". "Hace mucho tiempo que buscamos una garantía del gobierno para la restauración de nuestros derechos de ciudadanía antes de regresar. Para nuestra decepción, han evitado esta cuestión en el memorándum", dijo el activista político rohingya Ko Ko Linn a The Guardian (Shaikh Azizur Rahman, 2018).

Diplomáticos de alto nivel provenientes de los 15 países miembros del consejo de seguridad de la ONU viajaron a Myanmar en junio para evaluar y llevar a cabo actividades de difusión entre los refugiados acerca de las condiciones en Myanmar antes de tomar la decisión de regresar a Rakhine. El gobierno birmano insistió en que sólo los refugiados con los documentos de identidad correctos podrían regresar (Hunt, 2018). El portavoz de la LND, Myo Nyunt, dijo que llevar a cabo las medidas propuestas por la comunidad internacional produciría "manifestaciones en todo el país" (Kuhn, 2018). Por su parte, el ministro de la oficina de gobierno y asesor de seguridad nacional, Thaung Tun, declaró en una conferencia de seguridad regional en Singapur que la narrativa de los acontecimientos en Rakhine ha sido "incompleta y engañosa". "No se puede negar que la comunidad musulmana en Rakhine ha sufrido. Los budistas, hindúes y otras minorías étnicas no han sufrido menos" (Gopalakrishnan, 2018).

En un giro de postura política, y luego de haber suspendido las medidas restrictivas a Myanmar en 2012 para apoyar el cambio democrático, el 25 de junio la Unión Europea (UE) impuso sanciones a siete altos funcionarios militares birmanos, "por su participación o asociación en actos atroces y graves violaciones de derechos humanos cometidas contra la población rohingya en el estado Rakhine durante la segunda mitad de 2017”, de acuerdo con una declaración emitida por el consejo de la UE (Council of the European Union, 2018) (Emmott, 2018; Griffiths y Watson, 2018). ${ }^{8}$ Poco después del anuncio de la UE, Canadá sancionó a los mismos funcionarios militares. Sus sanciones impusieron la congelación de activos y prohibió a los canadienses y a otras personas en Canadá hacer tratos con los funcionarios enlistados (Global Affairs Canada, 2018; Slodkowski y Emmott, 2018). A las

${ }^{8}$ En febrero el consejo había condenado las "continuas y sistemáticas violaciones a los derechos humanos cometidas por las fuerzas militares y de seguridad birmanas", así como "los ataques del ARSA y otros grupos militantes", y llamado a "la rendición de cuentas y a crear las condiciones necesarias para el regreso de los refugiados a sus lugares de origen" (Council of the European Union, 2018). 
pocas horas de haberme emitido los comunicados de la UE y Canadá, y en un intento aparente por recuperar un poco de credibilidad, el tatmadaw anunció que el general Maung Maung Soe había sido despedido, mientras que otro general había dejado el ejército en mayo después de haber sido retirado de su puesto.

En julio el departamento de Relaciones Públicas y Guerra Psicológica del tatmadaw publicó el libro True News sobre la crisis de los rohingya. En este libro los militares niegan las acusaciones de abusos y culpan de la violencia a los "terroristas bengalís, cuya intención es forjar un estado rohingya llamado Arkistan". El autor, identificado como el teniente coronel Kyaw Kyaw Oo, afirma que el texto fue compilado usando fotos documentales con el objetivo de "revelar la historia de los bengalís", que han aprovechado "la incertidumbre de la transición democrática en Myanmar" (McPherson, 2018). Esto es, sin lugar a dudas, sólo una muestra más de las justificaciones [mal] maquinadas por el gobierno.

Durante su visita a Myanmar, el ministro de relaciones exteriores de Bangladesh, Abul Hassan Mahmood Ali, se reunió con autoridades del gobierno birmano en la capital del país y en el estado Rakhine. El 11 de agosto Myanmar anunció que había llegado a siete acuerdos con el ministro, incluyendo la promesa de "revisar el lenguaje utilizado en las tarjetas de verificación nacional (TVN) ${ }^{9}$ emitidas por Bangladesh", sin una explicación de por qué debería remplazarse. El ministro de bienestar social, Win Myat Aye, explicó que los refugiados no habían sido "desplazados por la fuerza", ya que "la mayoría de ellos no fueron expulsados por los militares, sino que se exiliaron gradualmente". Además de cambiar la redacción en la TVN, el gobierno birmano comunicó que Abul Hassan acordó establecer una línea directa entre los dos gobiernos, para discutir la repatriación y acelerar el proceso. Sin embargo, en un comunicado de prensa del ministerio de asuntos exteriores de Bangladesh no se menciona ningún acuerdo sobre el cambio de nomenclatura, y se usa dos veces el término "ciudadanos de Myanmar desplazados por la fuerza". Además, en el comunicado se explica que Bangladesh solicitó a Myanmar "ayuda para convencer a los posibles repatriados de aceptar las TVN" mediante el envío de equipos a los campos de refugiados para explicar sus

\footnotetext{
${ }^{9}$ Bangladesh comenzó a emitir las TVN desde septiembre de 2017, pero la mayoría de los rohingya se han negado a aceptarlas porque no los llama por su nombre y desconoce su grupo étnico. Las tarjetas, escritas en inglés, incluyen el nombre del titular, su edad, lugar de nacimiento, nacionalidad y nombre del padre y de la madre.
} 
ventajas (Moe Myint, 2018). Estas contradicciones en las declaraciones emitidas por cada gobierno aumentan las dudas sobre la seriedad en el proceso de repatriación.

A un año del inicio de la campaña militar en contra de los rohingya, el gobierno birmano expresó que la repatriación había alcanzado un nivel de seguridad óptimo. El embajador de Myanmar ante la ONU, Hau Do Suan, informó que Bangladesh había enviado al gobierno birmano una lista con 8000 nombres — de los cuales habían verificado 3000 -, y expresó que: "el gobierno ha entregado una lista de 1200 residentes verificados a Bangladesh y estamos esperando el inicio de la repatriación” (Besheer, 2018).

Sin embargo, la mayoría de los observadores internacionales opinan que las condiciones distan de ser las óptimas para comenzar el proceso de repatriación. A continuación se exponen algunas de las reacciones:

- Kobsak Chutikul, embajador retirado y ex miembro del parlamento de Tailandia, renunció en julio a su cargo como secretario del panel birmano para la investigación de la situación de los rohingya. Explicó que el panel, dentro del cual se encuentran expertos locales y extranjeros, se había "mantenido a raya", logrando muy poco avance en los seis meses que habían transcurrido desde su formación. Además, enfatizó que una propuesta para revisar la ley de ciudadanía no sería posible en esas circunstancias (McPherson y Naing, 2018).

- Según el Human Rights Watch, las autoridades birmanas han torturado y encarcelado a los refugiados que han regresado al estado Rakhine. El maltrato refuerza la necesidad de otorgar protección internacional y "es prueba de que la promesa del gobierno birmano para un retorno seguro y protegido es una mentira", expresó Phil Robertson, director adjunto para Asia: "Los rohingya que regresan aún se enfrentan a la persecución y los abusos que los obligaron a huir en un principio" (Human Rights Watch, 2018).

- En una declaración conjunta emitida por el parlamento de la ANSEA para los derechos humanos, 130 miembros de cinco países - Indonesia, Malasia, Filipinas, Timor Leste y Singapur - exigieron que el gobierno de Myanmar fuera investigado por la Corte Penal Internacional (CPI) con motivo de su “operación asesina en el estado Rakhine”. 
Charles Santiago, miembro del parlamento, pidió al consejo de seguridad de la ONU "remitir inmediatamente la situación a la CPI y hacer rendir cuentas a los responsables de estos horribles crímenes" (Ellis-Petersen, 2018).

- El secretario de Estado de los Estados Unidos, Mike Pompeo, expresó en Twitter: "Hace un año, después de los mortales ataques militantes, las fuerzas de seguridad respondieron lanzando una campaña de limpieza étnica aborrecible hacia los rohingya. Los Estados Unidos seguirán pidiendo la rendición de cuentas a los responsables” (McKay, R., 2018).

- Para el asesor especial sobre la prevención del genocidio de la ONU, Adama Dieng, “esto es algo que no podemos dejar de llamar limpieza étnica” (Besheer, 2018).

- John Fisher, director de Human Rights Watch en Ginebra, dijo que "el consejo de derechos humanos ( $\mathrm{CDH}$ ) debería enfatizar la responsabilidad del consejo de seguridad de la ONU para remitir a Myanmar ante la CPI y crear un órgano para la recopilación de pruebas que prepare los expedientes de juicios futuros” (Human Rights Watch, 2018).

La misión internacional de investigación independiente de la ONU en Myanmar publicó el 18 de septiembre el informe de los resultados a los que llegó en tres estados de Myanmar -Rakhine, Kachin y Shan — luego de 15 meses de indagación. Tras el lanzamiento del informe de 20 páginas ante el CDH el 27 de agosto, ${ }^{10}$ la misión publicó el informe completo de 440 páginas que establece patrones claros de violaciones por parte del tatmadaw, así como el análisis legal en el que se basan las recomendaciones. En el informe se nombra, además, a seis militares de alto rango para ser enjuiciados ante la CPI por "genocidio, crímenes de lesa humanidad y crímenes de guerra" — incluyendo al general Min Aung Hlaing — debido a las “operaciones de limpieza" puestas en marcha desde agosto de 2017. Además, se critica duramente a Aung San Suu Kyi por "no utilizar su posición de facto como jefa de gobierno, ni su autoridad moral, para detener o prevenir los acontecimientos en Rakhine”. También se especifica que algunos abusos fueron cometidos por grupos étnicos armados en los estados de Kachin y Shan, y por ARSA en Rakhine (UNHRC, 2018).

\footnotetext{
${ }^{10}$ La misión se creó en marzo de 2017 para investigar las denuncias generalizadas de abusos contra los derechos humanos en el país, particularmente en el estado de Rakhine. Los delitos documentados en los estados Kachin, Shan y Rakhine incluyen asesinatos, encarcelamientos, torturas, violaciones, persecuciones y esclavitud (Human Rights Council, 2018).
} 
Para la presidenta de la misión, Marzuki Darusman, en Myanmar "no se alcanzará la paz mientras el tatmadaw permanezca por encima de la ley", pues el ejército "es el mayor impedimento para el desarrollo del país como una nación democrática moderna". En el informe se detalla cómo la violencia perpetrada en contra de los rohingya y su expulsión masiva sólo pueden entenderse en un contexto de décadas de opresión y persecución institucionalizadas que han afectado sus vidas "desde el nacimiento hasta la muerte". La misión no tuvo acceso al país para completar el informe, sino que se valió de entrevistas con testigos, imágenes satelitales, fotografías y videos. Los investigadores encontraron elementos de exterminio y deportación "similares en naturaleza, gravedad y alcance a los que han permitido que se establezca la intención de genocidio en otros contextos". El informe sugiere el establecimiento de un organismo especial independiente de la ONU, que lleve a cabo una investigación para corroborar los crímenes cometidos. "A través de sus actos y omisiones, las autoridades civiles han contribuido a la consumación de delitos atroces", concluye el informe (UNHRC, 2018).

Minutos después de la publicación del informe, Facebook eliminó 18 cuentas y 52 páginas asociadas con el tatmadaw, incluida la del general Min Aung Hlaing. Al respecto, Facebook ha admitido que su reacción ante la crisis en Rakhine ha sido demasiado lenta, especialmente luego de reconocer su potencial como "instrumento para difundir el odio" contra las minorías (BBC, 2018). Investigadores de la ONU han indicado que el uso de Facebook desempeñó un "papel determinante" en la propagación del discurso de odio hacia los rohingya (BBC, 2018). ${ }^{11}$

El informe llamó a Amnistía Internacional, Human Rights Watch, Fortify Rights y Save the Children a fin de presionar para que los culpables sean investigados y juzgados por la CPI (Ellis-Petersen, 2018). Al día siguiente de la publicación, la fiscal de la CPI, Fatou Bensouda, declaró que la corte había decidido "llevar a cabo una investigación preliminar de la situación”. La investigación inicial, que podría conducir a una investigación formal, se centraría en una serie de supuestos "actos coercitivos" que llevaron al posible

\footnotetext{
${ }^{11}$ En Myanmar, Facebook es extremadamente popular, con más de 18 millones de usuarios. Si bien la conectividad a la internet ha explotado en los últimos cuatro años como resultado de la proliferación de teléfonos inteligentes y tarjetas SIM baratas, la alfabetización digital sigue siendo baja. Al mismo tiempo, las campañas de desinformación y el discurso de odio continúan sin control. Un informe de GSMA en 2016 - organismo global que representa a los operadores móvilesencontró que en Myanmar muchas personas consideraban a Facebook como el único punto de entrada de información en internet, y que muchas publicaciones se pensaban como noticias (Safi y Hogan, 2018). Pero el discurso de odio no sólo viene de los extremistas; los noticieros están repletos de publicaciones anti-rohingya compartidos por personas comunes, altos mandos militares y gobernantes civiles (Asian Correspondent, 2018).
} 
"desplazamiento forzado" de los musulmanes rohingya. Si bien Myanmar no se ha adherido a la CPI, los jueces dictaminaron que el tribunal aún tiene jurisdicción sobre los presuntos delitos contra los rohingya, en tanto Bangladesh sí es miembro. La fiscalía de la CPI argumentó que, a pesar de que los actos que obligaron a los rohingya a huir tuvieron lugar en Myanmar, el crimen no se completó hasta que los refugiados ingresaron a Bangladesh (BBC, 2018).

Tirana Hassan, directora de Amnistía Internacional, en respuesta a la crisis celebró la adopción de la resolución sobre Myanmar por el CDH de la ONU, como "un paso importante en la lucha por la rendición de cuentas" que busca "la posibilidad de justicia para los rohingya y otras minorías étnicas que han sufrido a manos de las fuerzas de seguridad del país". El intento de China por bloquear la resolución no fue posible ya que 35 países estuvieron a favor, 3 en contra y 7 se abstuvieron (Amnesty International, 2018).

El secretario de relaciones exteriores del Reino Unido, Jeremy Hunt, defendió la "difícil posición" del gobierno de Aung San Suu Kyi respecto a la crisis de los rohingya, mientras advirtió que el mundo no descansaría hasta que la minoría perseguida obtuviera justicia. Durante su visita de dos días a Myanmar, destacó la "atmósfera de miedo" que se vive en el estado Rakhine, y enfatizó que los refugiados rohingya en Bangladesh no deberían regresar a sus hogares hasta notar "un proceso judicial adecuado, rendición de cuentas y justicia para los perpetradores" (Smith, 2018).

El reclamo del gobierno estadounidense llegó acompañado de una investigación del departamento de Estado, que confirmó que el tatmadaw había emprendido desde 2017 "una campaña coordinada y bien planificada de asesinatos en masa, violaciones y otras atrocidades contra la minoría musulmana rohingya". Si bien el informe podría justificar nuevas sanciones y otras medidas punitivas contra las autoridades birmanas, parece que se quedó corto al no señalar las acciones como genocidio o como crímenes de lesa humanidad (Brunnstrom y Wroughton, 2018; Reuters, 2018). ${ }^{12}$

\footnotetext{
12 En noviembre de 2017, el gobierno estadounidense declaró que la violencia y las atrocidades contra los rohingya eran una campaña de "limpieza étnica", y el secretario de Estado, Rex Tillerson, señaló posibles sanciones. Pero el término "limpieza étnica" no se reconoce internacionalmente como un delito y no activa medidas punitivas contra Myanmar; otros han usado un lenguaje aún más fuerte para referirse a la violencia en el país: el presidente francés Emmanuel Macron lo ha llamado "genocidio"; Amnistía Internacional, "apartheid deshumanizante", y Human Rights Watch les refiere como "crímenes de lesa humanidad" (Morello y Bearak, 2017).
} 
Los estados miembros de ANSEA, que suelen regirse por el principio de no injerencia en asuntos internos, se unieron al llamado de la comunidad internacional en octubre para pedir el enjuiciamiento de los responsables. El primer ministro de Malasia, Mahathir Mohamad, dijo en entrevista a la cadena de televisión turca TRT World que "Aung San Suu Kyi había perdido su apoyo ante lo que parece ser un genocidio". Al margen de la asamblea general de la ONU en Nueva York, expresó que "aunque la política en la ANSEA es no intervenir en los asuntos internos de cada país, lo que está sucediendo es sumamente injusto y hemos expresado nuestra opinión". La ministra de relaciones exteriores de Singapur, Vivian Balakrishnan, dijo a su parlamento que, durante la reunión de ministros de relaciones exteriores de la ANSEA, los presentes expresaron su "grave preocupación ante los presuntos actos de violencia" (Boyle, 2018; Asian Correspondent, 2018).

El 15 de octubre la ACNUR presentó información que invitaba a reflexionar sobre la magnitud de la situación (véase la gráfica 2).

GRÁFICA 2. Cifras actuales sobre la situación de los rohingya en Bangladesh

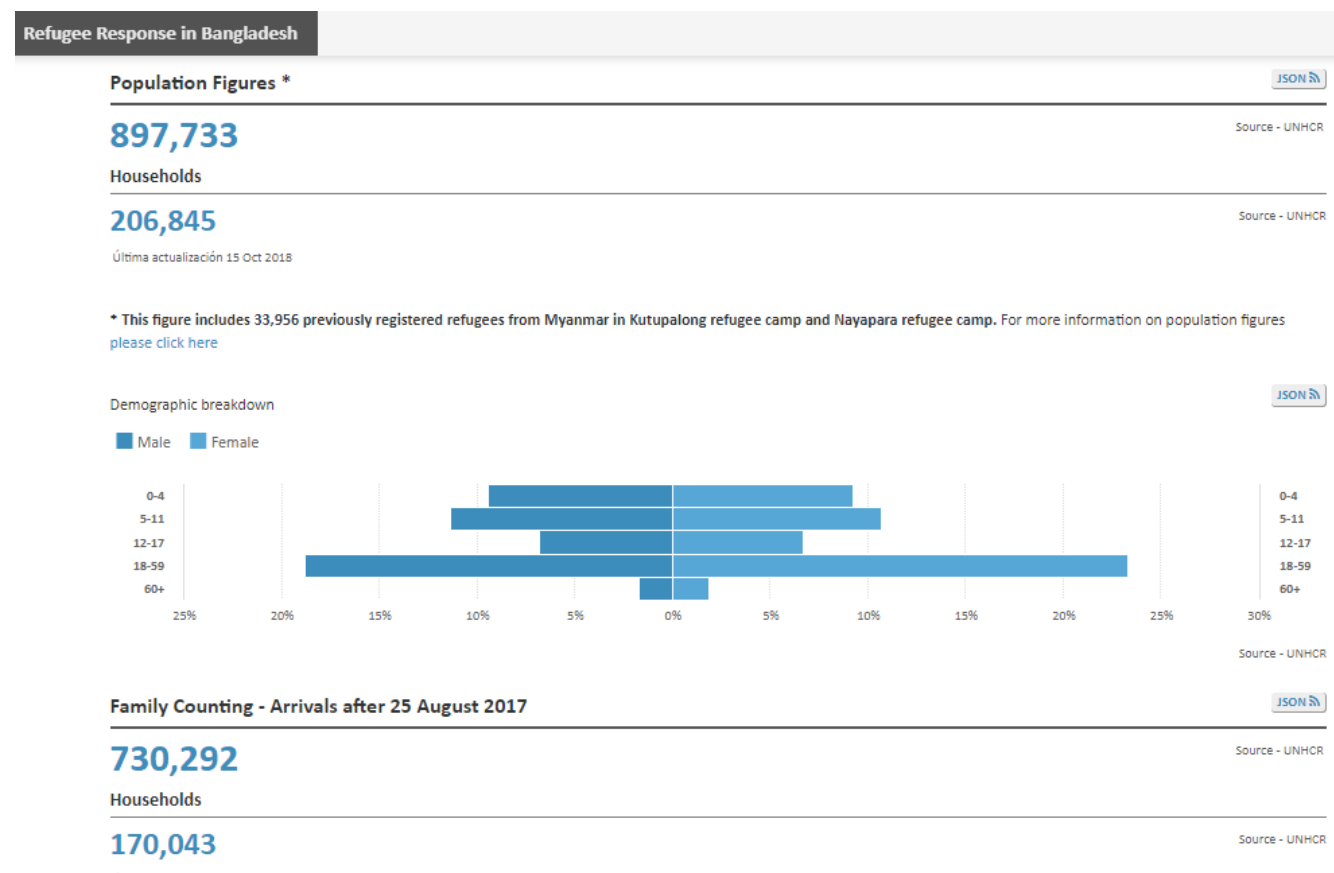

FUENTE: UNHCR (2018), Refugee Response in Bangladesh, UN Refugee Agency, 15 de octubre. Disponible en: https://data2.unhcr.org/es/situations/myanmar_refugees 
Ante la presión internacional y las crecientes demandas de rendición de cuentas, el gobierno de Myanmar articuló una defensa basada en la negación y el desafío. Para muchos, el intento del gobierno por cambiar la narrativa es una evidencia más de que no puede o no quiere corregir la situación (Mahtani, 2018). El gobierno, como era de esperarse, rechazó el informe de la misión y todas las acusaciones que ahí se detallaron, argumentando que sus militares lanzaron una operación legítima de contrainsurgencia. El portavoz del gobierno, Zaw Htay, comentó: "no permitimos que la misión entrara en Myanmar, por ello estamos en desacuerdo con las resoluciones hechas por la misión”, especialmente porque el país cuenta con su propia comisión independiente de investigación para responder a las "falsas acusaciones hechas por las agencias de la ONU y la comunidad internacional" (BBC, 2018). El informe fue calificado por el embajador de Myanmar en la ONU, Kyaw Moe Tun, como "unilateral e inválido". El gobierno insiste en que los musulmanes rohingya son inmigrantes ilegales que representan una amenaza para la seguridad del país y para la identidad nacional budista (BBC, 2018).

Sea limpieza étnica o genocidio, es claro que en Myanmar se están cometiendo violaciones a los derechos humanos de los rohingya, suficientes para invocar el principio responsabilidad de proteger (R2P), de conformidad con los capítulos VI, VII y VIII de la carta de las ONU que autorizan a la comunidad internacional a intervenir en la soberanía nacional de Myanmar.

\section{LOS CRISTIANOS EN KACHIN}

El grupo étnico kachin habita en el Estado o del mismo nombre, ubicado en la zona montañosa del norte de Myanmar, en los límites fronterizos entre China e India. En su mayoría, quienes pertenecen a la etnia kachin son cristianos. A diferencia de los rohingya, los kachin forman parte de las razas nacionales oficialmente reconocidas por el gobierno, reconocimiento que no ha sido suficiente para que sus derechos sean respetados y salvaguardados.

El conflicto armado entre los kachin y el tatmadaw es uno de los más antiguos. Durante siglos, los kachin vivieron en relativa calma, y no fue sino hasta la Segunda Guerra Mundial cuando diversos grupos cristianos apoyaron a los británicos en su lucha contra los japoneses, con el objetivo de alcanzar su independencia y autodeterminación, pues las tensiones entre 
el gobierno - en su mayoría pertenecientes a la etnia bamar-y los kachin fueron en aumento hasta estallar el conflicto armado luego de que los militares tomaron el poder en 1962. Los kachin formaron el Ejército de Independencia Kachin (KIA) mediante la Organización para la Independencia de Kachin (KIO), enfocada a defender su territorio.

Su campaña por una mayor autonomía es parte de una lucha mucho más amplia que enfrenta la mayoría étnica bamar contra docenas de minorías étnicas. Al menos 20 grupos han tomado las armas desde la independencia en 1948, y el gobierno ha firmado un alto el fuego con unos 10 de ellos en los últimos años (Pitman y Htusan, 2018). ${ }^{13}$

El estado Kachin se condujo con relativa independencia desde mediados de la década de 1960 hasta 1994, apoyado por una economía basada en el contrabando, el comercio de ámbar y jade con China, y los narcóticos. ${ }^{14}$ Luego de que el tatmadaw ocupara las minas de jade de la KIO en 1994, se firmó un tratado de paz que otorgó el control de la mayor parte del estado a la KIO, supervisado por el tatmadaw. Esta acción dividió a los kachin y llevó a término la tregua en 2011.

Según el informe de Fortify Rights, el gobierno ha estado manejando una estrategia invisible contra los kachin: el bloqueo de la ayuda a los que huyen del conflicto. Desde 2011, las autoridades de Myanmar han negado el acceso a los grupos de ayuda para las personas que habitan en áreas controladas por el KIA, aunque ocasionalmente permiten la entrada a lugares controlados por el tatmadaw (Fortify Rights, 2018). Esto, desde luego, ha aumentado el grado de vulnerabilidad de los kachin y los ha llevado a defender con mayor ímpetu su necesidad de independencia y autodeterminación.

En mayo las autoridades en Kachin informaron acerca de la evacuación de más de 130 de los 4000 habitantes del poblado de Mangwe - municipio de Karmine, distrito de Mohnyin - W . Win Zaw, legislador del distrito de Mohnyin, dijo que el gobierno y los militares transportaron a 133 desplazados internos (IDP o internally displaced people) atrapados en una zona de guerra a refugios temporales (Kyaw Myo Min y Zarni Htun, 2018). Según datos de la ONU, durante la primera mitad de 2018 unos 4000 kachin fueron expulsados de sus

\footnotetext{
${ }^{13}$ El gobierno ha solicitado a los grupos armados firmar el Acuerdo Nacional de Alto al Fuego (ANAF) negociado entre el gobierno y ocho grupos en octubre de 2015, pero el KIA no ha firmado.

${ }^{14}$ Las minas de ámbar y jade en el área son una valiosa fuente de ingresos para los kachin, recurso que ha financiado su rebelión y les ha permitido comprar armas al comerciar con sus vecinos extranjeros (Crawford, 2018). El monto de venta ilegal de jade, sin impuestos formales y generalmente contrabandeada a lo largo de la frontera con la provincia china de Yunnan, asciende a miles de millones (Hogan, 2018).
} 
hogares; estos desplazados se sumaron a los más de 120000 en los estados Kachin y Shan que permanecen atrapados en zonas de conflicto o que buscan refugio en la selva. Los kachin afirman que uno de cada ocho habitantes ha sido desplazado, y que miles han muerto en bombardeos y ataques llevados a cabo por el tatmadaw, ataques aleatorios e indiscriminados por tierra y aire que han ido en aumento desde principios de 2018, luego de que las fuerzas armadas pasaran meses expulsando a los rohingya de Rakhine (BBC, 2018; Hogan, 2018; Ryan, 2018),

"Hoy en día, la persecución étnica y religiosa continúa, tanto contra los rohingya como contra las minorías religiosas cristianas", afirma Olivia Enos, analista política del Centro de Estudios Asiáticos de la Heritage Foundation. "Los cristianos en los estados Karen, Kachin y Shan han permanecido en gran medida fuera del radar de la comunidad internacional, pero su situación es igualmente grave". A los cristianos en Myanmar les preocupa que, al permanecer a la sombra de los rohingya, el tatmadaw opere en su contra con impunidad (McKay, H., 2018).

Si bien la magnitud de los desplazamientos kachin no se comparan con el número de refugiados rohingya en Bangladesh, su situación no debe pasar desapercibida. Del mismo modo en que se han condenado las atrocidades contra los musulmanes, el sufrimiento de los cristianos debe investigarse, analizarse y llevarse ante la Corte Penal Internacional.

\section{¿LIBERTAD DE PRENSA?}

El 17 de abril el gobierno de Myanmar liberó a más de 8000 prisioneros en una amnistía programada para coincidir con la celebración del año nuevo birmano. El perdón fue firmado por el nuevo presidente de la Unión, Win Myint. La oficina del presidente informó, en un comunicado: "para llevar paz y alegría al corazón de la gente, y en busca del apoyo humanitario, se perdonará a 8490 prisioneros". Alrededor de 6000 contaban con denuncias por tráfico o consumo de drogas, aunque también se liberó a 36 presos políticos. Sin embargo, los dos periodistas de Reuters, Wa Lone y Kyaw Soe Oo, no formaron parte del grupo (Horner, 2018).

Wa Lone y Kyaw Soe Oo fueron arrestados el 12 de diciembre de 2017 luego reunirse con la policía para recibir algunos documentos. Los periodistas se encontraban recolectando 
evidencia sobre la ejecución de 10 hombres rohingya, mediante entrevistas con aldeanos budistas, personal de seguridad y fotografías. Las autoridades afirman que fueron arrestados "por poseer documentos gubernamentales importantes y secretos relacionados con el estado Rakhine y las fuerzas de seguridad", y que la información había sido "adquirida ilegalmente con la intención de compartirla con medios extranjeros" (Walden, 2017).

La investigación, publicada por Reuters el 8 de febrero, se centra en un episodio del 2 de septiembre de 2017 en el municipio de Inn Din, al norte de Rakhine, cuando un grupo de hombres rohingya que buscaban refugio en una playa fueron asesinados - dos de ellos por aldeanos budistas, el resto por disparos del ejército- y enterrados en una fosa que cavaron aldeanos budistas. Después de la detención de los periodistas, el ejército llevó a cabo su propia investigación sobre el incidente y pudieron corroborarse los hallazgos de Wa Lone y Kyaw Soe Oo.

A principios de 2018, el general Min Aung Hlaing emitió una declaración en la que afirmó que el ejército y algunos aldeanos eran responsables del asesinato de "10 terroristas bengalís", cuyos cuerpos fueron encontrados en una fosa común en Inn Din. El comunicado aclara que los "bengalís" fueron ejecutados ante la imposibilidad de ser transportados luego de los ataques a las estaciones de policía por el ARSA; además se explica que los soldados involucrados respondieron a "los terroristas que amenazaron y provocaron a los aldeanos budistas", y que "el ejército se encargaría de procesar a los responsables" (BBC, 2018; Richardson, A., 2018; Taylor, 2018). No fue sino hasta abril cuando tres oficiales y cuatro soldados fueron sentenciados a diez años de prisión con trabajos forzados, por su participación en la masacre de septiembre de 2017 (Reuters, 2018).

El 9 de julio, el juez del distrito de Yangon, Ye Lwin, acusó formalmente a los periodistas de violar la Ley de Secretos Oficiales promulgada en 1923 durante el periodo colonial. Los acusados se declararon inocentes y argumentaron que "seguían la ética periodística" (Richardson, A., 2018). El 3 de septiembre, Wa Lone y Kyaw Soe Oo fueron condenados y sentenciados a siete años de prisión por posesión de secretos oficiales, a pesar del testimonio de un oficial de policía que aseguraba que les habían tendido una trampa y que los documentos que les entregaron ya se habían hecho públicos. Antes de que terminara el juicio, Aung San Suu Kyi declaró públicamente que los reporteros eran culpables, y en una conversación privada con Bill Richardson los llamó "traidores" (Twitter, 2018). 
A mediados de septiembre, durante la conferencia del Foro Económico Mundial sobre la ANSEA en Hanói, Vietnam, Aung San Suu Kyi expresó que la sentencia a los periodistas no tenía nada que ver con la libertad de expresión. "No fueron encarcelados porque son periodistas, fueron encarcelados porque [...] el tribunal decidió que habían violado la Ley de Secretos Oficiales", y enfatizó que "el estado de derecho debe aplicar para todos [...] Si creemos en el estado de derecho, ellos pueden apelar y señalar por qué el fallo fue incorrecto" (Gerin, 2018: Smith, 2018). Días después de dictada la sentencia, el secretario general de la ONU pidió al gobierno de Myanmar la absolución y liberación de los periodistas lo antes posible: "Es inaceptable que estén encarcelados por cumplir con su trabajo" (Heavey y Brunnstrom, 2018).

El embajador de Estados Unidos ante la ONU, Nikki Haley, describió las declaraciones de Aung San Suu Kyi que defendían el encarcelamiento de dos periodistas de Reuters, como "increíbles": "Primero, negando el abuso de los militares hacia los rohingya, ahora justificaron el encarcelamiento de los dos reporteros de Reuters que informaron sobre la limpieza étnica. Increíble”, escribió Haley en su cuenta de Twitter (Reuters, 2018).

Los Estados Unidos, Francia, Gran Bretaña, la ONU, Amnistía Internacional, Human Rights Watch y grupos de la sociedad civil en Myanmar, criticaron las condenas impuestas a los periodistas e instaron al gobierno birmano a liberarlos. El vicepresidente estadounidense, Mike Pence, y el secretario de estado, Mike Pompeo, han pedido su liberación públicamente. No obstante, el gobierno ha ignorado todas estas peticiones de la misma manera como lo ha hecho con otras cuestiones que atentan contra su soberanía y autodeterminación, incluyendo los casos rohingya y kachin.

\section{CONCLUSIONES}

En 2018 los protagonistas en Myanmar fueron, por un lado, la consejera de estado, Aung San Suu Kyi, el presidente Win Min y el tatmadaw, y, por el otro, los rohingya, los kachin, los periodistas y todos sus defensores nacionales e internacionales.

En las primeras dos secciones pudo notarse el desprestigio en el que ha caído Aung San Suu Kyi, quien está en peligro de perder aquello que en su momento fue herramienta clave para su éxito político y el de su partido: su autoridad moral. Y es que la forma en que 
se han manejado los asuntos de las minorías rohingya y kachin, así como la censura periodística, no han hecho más que desconcertar a quienes guardaban sus esperanzas en una líder que parecía entender lo que significaba la represión y la injusticia. El papel del ejecutivo y del resto del gabinete civil pasó desapercibido. Los partidos democráticos en general, y la LND en particular, permanecen a la expectativa de los avances y resultados en temas de seguridad, economía y bienestar social. Al mismo tiempo, los militares y el tatmadaw se benefician del renacimiento de su popularidad, especialmente entre la mayoría budista, que se ha visto manipulada ante la creciente islamofobia.

Las tres secciones siguientes reafirmaron el poco compromiso del gobierno actual por hacer justicia a los desprotegidos. Aunque la campaña mediática hace parecer que los conflictos étnicos y las operaciones militares son recientes y justificados, la realidad es que la violencia contra las minorías ha sido una constante en el panorama sociopolítico de Myanmar desde su independencia en 1948, al rotar de una minoría a otra sin que los orígenes o religión parezcan significativos. ${ }^{15}$ Del mismo modo, la censura periodística en Myanmar ha permanecido en el país desde la toma de posesión del gobierno militar en 1962; la diferencia ahora es el impacto que la censura tiene a escala internacional y el apoyo que genera dentro y fuera de Myanmar. Estas problemáticas, al igual que la forma en que se han resuelto, no son algo nuevo. Ante una situación difícil, el gobierno continúa ignorando las acusaciones y fortaleciendo sus vínculos con aquéllos a quienes considera sus aliados.

Un escenario sobre el futuro del país tendría al menos una de las siguientes variables:

1. El regreso a la dominación política militar, aunque ahora por demanda popular mediante mecanismos democrático.

2. Un aumento de la represión hacia quienes critiquen o contravengan al gobierno.

3. El retorno al ostracismo del periodo militar ante la creciente presión internacional y la sordera del gobierno birmano.

Gobiernos y organizaciones internacionales han sancionado a Myanmar y han tomado represalias contra el gobierno y sus representantes. Sin embargo, ninguna acción parece

15 En años recientes las operaciones militares parecen seguir el curso de las manecillas de reloj a lo largo de provincias fronterizas: desde el estado occidental Rakhine contra los rohingya, continuando con los cristianos y otros grupos étnicos minoritarios en el vecino estado Chin, pasando al estado septentrional Kachin y su Ejército de Independencia Kachin (KIA) procristiano, siguiendo hacia la región sureste del estado Shan y terminando en el sureño estado Karen (Kayin). 
suficiente y todo apunta a un futuro no muy favorable para las minorías étnicas, para la libertad de prensa y para la población local.

\section{REFERENCIAS CONSULTADAS}

ACNUR (2018), “ACNUR y PNUD concuerdan el texto del Acuerdo de Entendimiento tripartito con Myanmar para apoyar la creación de condiciones para el regreso de los refugiados rohingya”, ACNUR, 31 de mayo. Disponible en: http://www.acnur.org/noticias/press/2018/5/5b118a3d4/acnur-y-pnud-concuerdan-eltexto-del-acuerdo-de-entendimiento-tripartito.html\#_ga=2.200186158.1814485005

AFP (2018), “Canada Accuses Myanmar of Genocide Against Rohingya”, The Guardian, 20 de septiembre. Disponible en: https:/www.theguardian.com/world/2018/sep/21/canada-accuses-myanmar-ofgenocide-against-rohingya

AFP (2018), "Myanmar president pledges to amend army-scripted constitution", $A B S-C B N, 30$ de marzo. Disponible en: https://news.abs-cbn.com/overseas/03/30/18/myanmarpresident-pledges-to-amend-army-scripted-constitution

Agerholm, H. (2018), "Myanmar elects Aung San Suu Kyi aide Win Myint as president", The Independent, 28 de marzo. Disponible en: https://www.independent.co.uk/news/world/asia/myanmar-new-president-aung-sansuu-kyi-win-myint-rohingya-military-a8277231.html

Al Jazeera (2017), “UN rights chief denounces Myanmar's ethnic cleansing”, Al Jazeera, 12 de septiembre. Disponible en: https://www.aljazeera.com/news/2017/09/myanmarcrisis-textbook-ethnic-cleansing-170911081528888.html

Al Jazeera (2018), “Rohingya 'ethnic cleansing in Myanmar continues': UN”, Al Jazeera, 6 de marzo. Disponible en: https://www.aljazeera.com/news/2018/03/rohingya-ethniccleansing-myanmar-continues-180306062135668.html

Al Jazeera (2018), “Undercover for Revision: Reporting Myanmar's Rohingya story”, Al Jazeera, 29 de abril. Disponible en: 
https://www.aljazeera.com/programmes/listeningpost/2018/04/undercover-rvisionreporting-myanmar-rohingya-story-180428121312418.html

Amnesty International (2018), “UN: Major step towards accountability for atrocity crimes in Myanmar". Amnesty International, 27 de septiembre. Disponible en: https://www.amnesty.org/en/latest/news/2018/09/un-amnesty-reaction-to-hrcresolution-on-myanmar/

ANU (2018), Australian National University, 28 de septiembre. Disponible en: Maps Online: ANU College of Asia and the Pacific: http://asiapacific.anu.edu.au/mapsonline/basemaps/myanmar-statesregions

AP (2018), "Evidence of Rohingya mass graves uncovered in Myanmar", Al Jazeera, 1 de febrero. Disponible en: https://www.aljazeera.com/news/2018/02/evidence-rohingyamass-graves-uncovered-myanmar-180201052413608.html

Asian Correspondent (2018), “Asean ministers raise heat on Burma's Rohingya crisis”, Asian Correspondent, 3 de octubre. Disponible en: https://asiancorrespondent.com/2018/10/asean-ministers-raise-heat-on-burmasrohingya-crisis/

Asian Correspondent (2018), "Burma's Bin Laden and the spread of anti-Muslim hate speech", Asian Correspondent, 2 de marzo. Disponible en: https://asiancorrespondent.com/2018/03/burmese-bin-laden-proliferation-antimuslim-hate-speech-burma/

Baldwin, C. (2018), "The Rohingya lists: refugees compile their own record of those killed in Myanmar", Reuters, 17 de agosto. Disponible en: https://www.reuters.com/article/us-myanmar-rohingya-lists-insight/the-rohingyalists-refugees-compile-their-own-record-of-those-killed-in-myanmar

BBC (2018), “Aung San Suu Kyi stripped of Edinburgh honour”, $B B C$. Disponible en: https://www.bbc.com/news/uk-scotland-edinburgh-east-fife-45280546

BBC (2018), "Aung San Suu Kyi: The democracy icon who fell from grace”, $B B C, 13$ de septiembre. Disponible en: https://www.bbc.com/news/world-asia-pacific-11685977 
BBC (2018), "How Aung San Suu Kyi sees the Rohingya crisis", BBC, 25 de enero. Disponible en: https://www.bbc.com/news/world-asia-42824778

BBC (2018), “ICC opens Myanmar Rohingya crimes probe”, BBC, 19 de septiembre. Disponible en: https://www.bbc.com/news/world-asia-45568946

BBC (2018), "Myanmar rejects UN accusation of 'genocide' against Rohingya”, BBC, 29 de agosto. Disponible en: https://www.bbc.com/news/world-asia-45338986

BBC (2018), “Myanmar Rohingya: Why Facebook banned an army chief”, BBC, 28 de agosto. Disponible en: https://www.bbc.com/news/world-asia-45326928

BBC (2018), "Myanmar violence: Thousands flee fresh fighting in Kachin state”, $B B C, 28$ de abril.

BBC (2018), "Rohingya crisis: Myanmar to try Reuters journalists who reported on massacre”, $B B C, 9$ de julio. Disponible en: https://www.bbc.com/news/world-asia-44762425

BBC (2018), “UN: Facebook has turned into a beast in Myanmar", BBC, 13 de marzo. Disponible en: https://www.bbc.com/news/technology-43385677

Beech, H. (2018), "Myanmar and U.N. Agree to Aim for Repatriation of Rohingya”, The New York Times, 31 de mayo. Disponible en: https://www.nytimes.com/2018/05/31/world/asia/myanmar-rohingya-refugeesreturn.html

Besheer, M. (2018), “One Year After Fleeing, Rohingya Refugees Say Myanmar Still Unsafe", Voice of America, 24 de agosto. Disponible en: https://www.voanews.com/a/rohingya-refugees-say-myanmar-stillunsafe/4542185.html

Boyle, D. (2018), “ASEAN Talks Tough on Rohingya Crisis”, Voice of America, 5 de octubre. Disponible en: https:/www.voanews.com/a/asean-talks-tough-rohingyacrisis/4601349.html

Brunnstrom, D. y L.Wroughton, (2018), “Those responsible for Myanmar crimes could face genocide charges: U.S.”, Reuters, 27 de septiembre. Disponible en: 
https://www.reuters.com/article/us-usa-myanmar-rohingya/those-responsible-formyanmar-crimes-could-face-genocide-charges-us-idUSKCN1M72VA

Channel NewsAsia (2018), “Aung San Suu Kyi loyalist Win Myint elected Myanmar president", Channel NewsAsia, 28 de marzo. Disponible en: https://www.channelnewsasia.com/news/asia/myanmar-president-win-myint-aungsan-suu-kyi-ally-10083324

CIA (2018), Central Intelligence Agency, 17 de octubre. Disponible en: The World Factbook: Burma: https://www.cia.gov/library/publications/the-world-factbook/geos/bm.html

Council of the European Union (2018), "Myanmar/Burma: Council adopts conclusions", European Council, 26 de febrero. Disponible en: https://www.consilium.europa.eu/en/press/press-releases/2018/02/26/myanmarburma-council-adopts-conclusions/

Council of the European Union (2018), "Myanmar/Burma: EU sanctions 7 senior military, border guard and police officials responsible for or associated with serious human rights violations against Rohingya population", Council of the European Union, 25 de junio. Disponible en: https://www.consilium.europa.eu/en/press/pressreleases/2018/06/25/myanmar-burma-eu-sanctions-7-senior-military-border-guardand-police-officials-responsible-for-or-associated-with-serious-human-rightsviolations-against-rohingya-population/pdf

Crawford, A. (2018), 'Uncovered: 'Worrying evidence' of new genocidal campaign on Kachin Christian minority in Myanmar", Sky News, 5 de junio. Disponible en: https://news.sky.com/story/uncovered-worrying-evidence-of-new-genocidalcampaign-in-myanmar-11395173

Dangerfield, K. (2018), "Myanmar leader stripped of 7th award over Rohingya crisis - still has honorary Canadian status", Global News, 23 de agosto. Disponible en: https://globalnews.ca/news/4404212/myanmar-leader-aung-san-suu-kyi-strippededinburgh-award/

Eckert, P. (2018), “Aung San Suu Kyi Calls For New Strategy, Patience in Myanmar Peace Talks", Radio Free Asia, 16 de julio. Disponible en: https://www.rfa.org/english/news/myanmar/assk-talks-07162018164840.html 
Ellis-Petersen, H. (2018), "Myanmar's military accused of genocide in damning UN report", The Guardian, 27 de agosto. Disponible en: https://www.theguardian.com/world/2018/aug/27/myanmars-military-accused-ofgenocide-by-damning-un-report

Ellis-Petersen, H. (2018a), "Rohingya crisis: 132 MPs across region call for Myanmar to be referred to ICC", The Guardian, 24 de agosto. Disponible en: https://www.theguardian.com/world/2018/aug/24/rohingya-crisis-132-mps-acrossregion-call-for-myanmar-to-be-referred-to-icc

Emmott, R. (2018), “EU Penalizes Myanmar Generals for Rohingya Violations”, Jakarta Globe, 26 de junio. Disponible en: https://jakartaglobe.id/international/eu-penalizesmyanmar-generals-rohingya-violations/

Encyclopædia Britannica (2018), Myanmar: Religious affiliation, 5 de octubre. Disponible en: https://www.britannica.com/place/Myanmar/Languages/media/400119/224192

Fortify Rights (2018), “They Block Everything. Avoidable Deprivations in Humanitarian Aid to Ethnic Civilians Displaced by War in Kachin State, Myanmar. Fortify Rights", Disponible en: https://www.fortifyrights.org/downloads/They_Block_Everything_EN_Fortify_Right s_August_2018.pdf

Gerin, R. (2018), “Aung San Suu Kyi Says Rohingya Crisis 'Could Have Been Handled Better, Radio Free Asia, 13 de septiembre. Disponible en: https://www.rfa.org/english/news/myanmar/aung-san-suu-kyi-says-rohingya-crisiscould-have-been-better-handled-09132018164001.html

Global Affairs Canada (2018), "Canada imposes further sanctions in response to ongoing crisis in Myanmar", Government of Canada, 25 de junio. Disponible en: https://www.canada.ca/en/global-affairs/news/2018/06/canada-imposes-furthersanctions-in-response-to-ongoing-crisis-in-myanmar.html

Gopalakrishnan, R. (2018), "Myanmar says willing to take back all Rohingya refugees", Reuters, 2 de junio. Disponible en: https://www.reuters.com/article/us-asia-securitymyanmar/myanmar-says-willing-to-take-back-all-rohingya-refugeesidUSKCN1IY0AS 
Griffiths, J., \& Watson, A. (2018), "Myanmar fires general in charge of Rohingya crackdown after EU sanctions", $C N N, 26$ de junio. Disponible en: https://edition.cnn.com/2018/06/26/asia/myanmar-military-rohingya-generalintl/index.html

Heavey, S., y Brunnstrom, D. (2018), “U.N. chief urges Myanmar government to free Reuters journalists", 20 de septiembre. Disponible en: https://www.reuters.com/article/usmyanmar-journalists-un/u-n-chief-urges-myanmar-government-to-free-reutersjournalists-idUSKCN1M02OG

Hogan, L. (2018), “'Slow genocide': Myanmar's invisible war on the Kachin Christian minority", The Guardian, 14 de mayo. Disponible en: https://www.theguardian.com/world/2018/may/14/slow-genocide-myanmarsinvisible-war-on-the-kachin-christian-minority

Horner, W. (2018), "Burma frees 8,500 prisoners in holiday amnesty", The Telegraph, 17 de abril. Disponible en: https://www.telegraph.co.uk/news/2018/04/17/burma-frees8500-prisoners-holiday-amnesty/

Human Rights Council (2018). Report of the independent international fact-finding mission on Myanmar. Thirty-ninth session, Agenda item 4 . Ginebra: Human Rights Council . Disponible en: https://www.ohchr.org/Documents/HRBodies/HRCouncil/FFMMyanmar/A_HRC_39_64.pdf

Human Rights Watch (2017), "Burma: New Satellite Images Confirm Mass Destruction", Human Rights Watch, 17 de octubre. Disponible en: https://www.hrw.org/news/2017/10/17/burma-new-satellite-images-confirm-massdestruction

Human Rights Watch (2018), "Myanmar: Security Forces Torture Rohingya Returnees", Human Rights Watch, 21 de agosto. Disponible en: https://www.hrw.org/news/2018/08/21/myanmar-security-forces-torture-rohingyareturnees

Human Rights Watch (2018), “UN Rights Council: Secure Justice for Myanmar Victims", Human Rights Watch, 10 de septiembre. Disponible en: 
https://www.hrw.org/news/2018/09/10/un-rights-council-secure-justice-myanmarvictims

Hunt, L. (2018), "New UN-Myanmar Agreement, Same Old Rohingya Plight", The Diplomat, 22 de junio. Disponible en: https://thediplomat.com/2018/06/new-un-myanmaragreement-same-old-rohingya-plight/

John, G. y F. Ungku (2018), "Myanmar's Suu Kyi says relations with military 'not that bad', Reuters, 21 de agosto. Disponible en: https://www.reuters.com/article/us-singaporemyanmar-suukyi/myanmars-suu-kyi-says-relations-with-military-not-that-badidUSKCN1L60OP

Kipgen, N. (2013). Conflict in Rakhine State in Myanmar: Rohingya Muslims Conundrum. Journal of Muslims Minority Affairs, 33(2), pp. 298-310.

Kuhn, A. (2018), "Rohingya Crisis Is Making Some In Myanmar Rethink Their Views Of Aung San Suu Kyi”, NPR, 21 de junio. Disponible en: https://www.npr.org/2018/06/21/621762181/rohingya-crisis-is-making-some-inmyanmar-rethink-their-views-of-aung-san-suu-ky

Kyaw Myo Min y Zarni Htun (2018), "Kachin State Evacuates More Than 130 Civilians Trapped by Fighting in Northern Myanmar", Radio Free Asia", Disponible en: https://www.rfa.org/english/news/myanmar/kachin-state-evacuates-more-than-130civilians-trapped-by-fighting-in-northern-myanmar-05072018161531.html

Lee, Y., Aye Win Myint, y Shoon Naing (2018), “U.N. chief 'shocked' by top Myanmar general's comments on Rohingya", Reuters, 27 de marzo. Disponible en: https://www.reuters.com/article/us-myanmar-rohingya-un/u-n-chief-shocked-by-topmyanmar-generals-comments-on-rohingya-idUSKBN1H31VK

Mahtani, S. (2018), “The world decries Myanmar's Rohingya abuses. Myanmar's reply: Denial, defiance and propaganda", The Washington Post, 9 de octubre. Disponible en: https://www.washingtonpost.com/world/asia_pacific/the-world-decries-myanmarsrohingya-abuses-myanmars-reply-denial-defiance-andpropaganda/2018/10/09/49d11916-c1b9-11e8-9451e878f96be19b_story.html?noredirect $=$ on\&utm_term $=.01 \mathrm{dd} 56 \mathrm{c} 36 \mathrm{fd} 6$ 
McKay, H. (2018), "With world's attention on Rohingya Muslims, Christians in Burma also face brutal persecution", Fox News, 17 de agosto. Disponible en: https://www.foxnews.com/world/with-worlds-attention-on-rohingya-muslimschristians-in-burma-also-face-brutal-persecution

McKay, R. (2018), "Pompeo decries 'abhorrent ethnic cleansing' in Myanmar on anniversary", Reuters, 26 de agosto. Disponible en: https://www.reuters.com/article/us-myanmar-rohingya-anniversary-usa/pompeodecries-abhorrent-ethnic-cleansing-in-myanmar-on-anniversary-idUSKCN1LB06V

McPherson, P. (2018), “Exclusive: Fake photos in Myanmar army's 'True News' book on the Rohingya crisis", Reuters, 30 de agosto. Disponible en: https://www.reuters.com/article/us-myanmar-rohingya-photos-exclusive/exclusivefake-photos-in-myanmar-armys-true-news-book-on-the-rohingya-crisisidUSKCN1LF2LB

McPherson, P., y S. Naing (2018), "Exclusive: Citing lack of progress, secretary to Myanmar's Rohingya panel quits", Reuters, 20 de julio. Disponible en: https://www.reuters.com/article/us-myanmar-rohingya-panel-exclusive/exclusiveciting-lack-of-progress-secretary-to-myanmars-rohingya-panel-quitsidUSKBN1KA2IB

Moe Myint (2018), "Myanmar Asks Bangladesh to Stop Calling Rohingya Refugees 'Nationals', 'Forcibly Displaced', The Irrawaddy, 14 de agosto. Disponible en: https://www.irrawaddy.com/news/burma/myanmar-asks-bangladesh-stop-callingrohingya-refugees-nationals-forcibly-displaced.html

Moe Myint (2018), "Ninety Percent of Rohingya Population Ejected from Rakhine. The Irrawaddy. Disponible en: https://www.irrawaddy.com/specials/ninety-percentrohingya-population-ejected-rakhine.html

Morello, C., y M. Bearak (2017), "U.S. declares attacks on Burmese Rohingya Muslims 'ethnic cleansing", The Washington Post, 22 de noviembre. Disponible en: https://www.washingtonpost.com/world/us-declares-attacks-on-burmese-rohingyamuslims-ethnic-cleansing/2017/11/22/cfde1a32-cfd8-11e7-81bcc55a220c8cbe_story.html?noredirect $=$ on\&utm_term $=.3 \mathrm{f} 6 \mathrm{a} 0002 \mathrm{f} 14 \mathrm{f}$ 
NHK World News (2018), “Exclusive: Interview with Aung San Suu Kyi”, NHK World News, 8 de junio. Disponible en: https://www3.nhk.or.jp/nhkworld/en/news/editors/1/exclusiveaungsansuukyi/index.ht $\mathrm{ml}$

Paddock, R. (2018), "From Hero to Pariah, Aung San Suu Kyi Dashes Hopes About Myanmar", The New York Times, 29 de septiembre. Disponible en: https://www.nytimes.com/2018/09/29/world/asia/myanmar-aung-san-suu-kyirohingya.html

Paddock, R., y S. Nang (2018), "Myanmar Picks a New President, but He'll Still Be No. 2", The New York Times, 28 de marzo. Disponible en: https://www.nytimes.com/2018/03/28/world/asia/myanmar-president-u-winmyint.html

Pitman, T., y Htusan, E. (2018), "In northern Myanmar, forgotten Kachin conflict intensifies", AP News, 25 de abril. Disponible en: https://www.apnews.com/8de0691e3373448ba62bc778a877ee8f

Reuters (2018), “Aung San Suu Kyi won't be stripped of Nobel Peace prize, says head of foundation", The Independent, 2 de octubre. Disponible en: https://www.independent.co.uk/news/world/asia/aung-sun-suu-kyi-nobel-peace-prizeburma-myanmar-rohingya-massacre-a8564861.html

Reuters (2018), "Haley: Suu Kyi's defense of jailing of journalists 'unbelievable", The Asahi Shimbun, 14 de septiembre. Disponible en: http://www.asahi.com/ajw/articles/AJ201809140044.html

Reuters (2018), "Myanmar Not Ready For Return of Rohingya Refugees: UN Official”, The Irrawaddy, 9 de abril. Disponible en: https://www.irrawaddy.com/news/burma/myanmar-not-ready-return-rohingyarefugees-un-official.html

Reuters (2018), "Myanmar soldiers jailed for 10 years over massacre of Rohingya Muslims", The Guardian, 10 de abril. Disponible en: https://www.theguardian.com/world/2018/apr/10/myanmar-rohingya-muslimsmassacre-burma-soldiers-sentenced-jailed 
Reuters (2018), "Report blames Myanmar army for 'large-scale' attacks on Rohingya", $A l$ Jazeera, $\quad 24$ de septiembre. Disponible en: https://www.aljazeera.com/news/2018/09/report-blames-myanmar-army-large-scaleattacks-rohingya-180924195602630.html

Richards, E. (2018), "Burma: President resigns with immediate effect", Asian Correspondent, 21 de marzo. Disponible en: https://asiancorrespondent.com/2018/03/burma-presidentresigns-with-immediate-effect/

Richardson, A. (2018), “Timeline: Reuters journalists detained in Myanmar”, Reuters, 25 de agosto.

Richardson, B. (2018), "Bill Richardson: How the West Can Help Fix the Rohingya Crisis", Time, 15 de febrero. Disponible en: http://time.com/5158603/bill-richardsonmyanmar-rohingya-bangladesh/

Ryan, L. (2018), "Burma/Myanmar violence: From the Rohingya to the Kachin”, News REP, 10 de junio. Disponible en: https://thenewsrep.com/104378/burma-myanmar-violencefrom-the-rohingya-to-the-kachin/

Safi, M. (2018), "First Rohingya refugees repatriated to Myanmar despite UN safety fears", The Guardian, 15 de abril. Disponible en: https://www.theguardian.com/world/2018/apr/15/first-rohingya-refugees-repatriatedto-myanmar-despite-un-safety-fears

Safi, M. (2018), "ICC says it can prosecute Myanmar for alleged Rohingya crimes", The Guardian, 6 de septiembre. Disponible en: https://www.theguardian.com/world/2018/sep/06/icc-says-it-can-prosecute-myanmarfor-alleged-rohingya-crimes

Safi, M., y L. Hogan (2018), "Revealed: Facebook hate speech exploded in Myanmar during Rohingya crisis", The Guardian, 3 de abril. Disponible en: https://www.theguardian.com/world/2018/apr/03/revealed-facebook-hate-speechexploded-in-myanmar-during-rohingya-crisis 
San Yamin Aung (2018), "Who is U Win Myint, Myanmar's Likely New President?”, The Irrawaddy, 26 de marzo. Disponible en: https://www.irrawaddy.com/news/burma/uwin-myint-myanmars-likely-new-president.html

Shaikh Azizur Rahman (2018), "Rohingya refugees reject UN-Myanmar repatriation agreement", The Guardian, 6 de julio. Disponible en: https://www.theguardian.com/world/2018/jul/06/rohingya-refugees-reject-unmyanmar-repatriation-agreement

Siddiqui, Z., Slodkowski, A. (2018), “A year on, Rohingya still fleeing Myanmar for crowded camps", Reuters, 22 de agosto. Disponible en: https://www.reuters.com/article/us-myanmar-rohingya-anniversary/a-year-onrohingya-still-fleeing-myanmar-for-crowded-camps-idUSKCN1L802H

Slodkowski, A., y R. Emmott (2018), "EU, Canada sanction Myanmar generals over Rohingya; Myanmar says two are fired”, Reuters, 25 de junio. Disponible en: https://www.reuters.com/article/us-myanmar-eu/eu-to-penalize-myanmar-officialsover-rohingya-violations-idUSKBN1JL0SC

Slodkowski, A., y Thu Thu Aung (2018), "Suu Kyi loyalist seen replacing Myanmar's sick president - ruling party spokesman", Reuters, 20 de marzo. Disponible en: https://uk.reuters.com/article/uk-myanmar-politics-president/suu-kyi-loyalist-seenreplacing-myanmars-sick-president-ruling-party-spokesmanidUKKBN1GX0EG?il=0

Smith, N. (2018), “Aung San Suu Kyi defends jailing of Burmese journalists”, The Telegraph, 13 de septiembre. Disponible en: https:/www.telegraph.co.uk/news/2018/09/13/aungsan-suu-kyi-defends-jailing-burmese-journalists/

Smith, N. (2018), “Jeremy Hunt defends Suu Kyi's 'difficult position' but says Rohingya need justice", The Telegraph, 20 de septiembre. Disponible en: https://www.telegraph.co.uk/news/2018/09/20/jeremy-hunt-indicates-uk-maysupport-icc-referral-rohingya-atrocities/

South China Morning Post (2018), “Myanmar's Aung San Suu Kyi says the country is ready to receive 'verified' Rohingya refugees", South China Morning Post, 1 de mayo. 
Disponible en: https://www.scmp.com/news/asia/southeastasia/article/2144108/myanmars-suu-kyi-says-country-ready-receive-verified

Steinberg, D. I. (2018), "Myanmar: Aung San Suu Kyi and the Cult of Personality", The Diplomat, 14 de julio. Disponible en: https://thediplomat.com/2018/07/myanmaraung-san-suu-kyi-and-the-cult-of-personality/?allpages=yes\&print=yes

Tan Hui Yee (2018), “Myanmar citizens now have more confidence, says Suu Kyi”, The Straits Time, 14 de septiembre. Disponible en: https:/www.straitstimes.com/asia/seasia/myanmar-citizens-now-have-more-confidence-says-suu-kyi

Taylor, A. (2018), "In a first, Burmese military admits that soldiers killed Rohingya found in mass grave", The Washington Post, 10 de enero. Disponible en: https://www.washingtonpost.com/news/worldviews/wp/2018/01/10/in-a-firstburmese-military-admits-soldiers-killed-rohingya-found-in-massgrave/?utm_term $=.288 \mathrm{dc} 017 \mathrm{fbba}$

Tun Khin (2018), “The Rohingya's hope for justice lies with the ICC", Al Jazeera, 20 de mayo. Disponible en: https:/www.aljazeera.com/indepth/opinion/rohingya-hopejustice-lies-icc-180520115612174.html?xif=1/4

Twitter (2018), Bill Richardson, 3 de septiembre. Disponible en: https://twitter.com/GovRichardson/status/1036621048194584576

UN News (2017), “UN human rights chief points to 'textbook example of ethnic cleansing' in Myanmar", UN News, 2017 de septiembre. Disponible en: https://news.un.org/en/story/2017/09/564622-un-human-rights-chief-points-textbookexample-ethnic-cleansing-myanmar

UN News (2018), “'Sharp escalation' in fighting across Myanmar's Kachin state, warns rights expert", $\quad U N$ News, 1 de mayo. Disponible en: https://news.un.org/en/story/2018/05/1008642

UNHCR (2018), Agencia de las Naciones Unidas para los Refugiados, octubre. Disponible en: Internally Displaced People: http://www.unhcr.org/internally-displacedpeople.html 
UNHCR (2018), Refugee Response in Bangladesh, 15 de octubre. Disponible en: UN Refugee Agency: https://data2.unhcr.org/es/situations/myanmar_refugees

UNHCR (2018), “UNHCR and UNDP urge tangible progress to improve conditions in Myanmar's Rakhine State", UNHCR, 8 de agosto. Disponible en: http://www.unhcr.org/news/press/2018/8/5b6a9ac64/unhcr-undp-urge-tangibleprogress-improve-conditions-myanmars-rakhine-state.html

UNHRC (2018), Report of Independent International Fact-Finding Mission on Myanmar. Ginebra: UNHRC, 18 de septiembre. Disponible en: https://www.ohchr.org/EN/HRBodies/HRC/MyanmarFFM/Pages/ReportoftheMyanm arFFM.aspx

Wa Lone, y Shoon Naing (2017), “At least 71 killed in Myanmar as Rohingya insurgents stage major attack", Reuters, 24 de agosto. Disponible en: https://www.reuters.com/article/us-myanmar-rohingya/at-least-71-killed-inmyanmar-as-rohingya-insurgents-stage-major-attack-idUSKCN1B507K

Wai Mar Tun (2018), "Myanmar Agrees to UN Agency Plan For Repatriating Rohingya Refugees", Radio Free Asia, 30 de marzo. Disponible en: https://www.rfa.org/english/news/myanmar/myanmar-agrees-to-un-plan-forrepatriating-rohingya-refugees-03302018161152.html

Walden, M (14 de diciembre de 2017). Burma arrests two Reuters journalists covering Rohingya crisis. Asian Correspondent. Disponible en: https://asiancorrespondent.com/2017/12/burma-arrests-two-reuters-journalistscovering-rohingya-crisis/ 